\title{
Uniparental Disomy
}

National Cancer Institute

\section{Source}

National Cancer Institute. Uniparental Disomy. NCI Thesaurus. Code C85215.

A condition characterized by the inheritance of a chromosome pair from one parent and no chromosomal copies from the other parent. It results in developmental abnormalities or rare recessive disorders. Examples of uniparental disomy include the Prader-Willi syndrome and Angelman syndrome. 